\title{
Medical students' perspectives on recommencing clinical rotations during coronavirus disease 2019 at one institution in South Korea
}

\author{
Jewel Park'1, Hyunmi Park' ${ }^{2}$ Ji-Eun Lim', Hye Chang Rhim ${ }^{3}$ and Young-Mee Lee ${ }^{2}$ \\ ${ }^{1}$ Korea University College of Medicine, ${ }^{2}$ Department of Medical Education, Korea University College of Medicine, \\ Seoul, Korea, and ${ }^{3}$ Harvard T.H Chan School of Public Health, Boston, MA, USA
}

Purpose: Clinical rotations of medical students across the world have inevitably been affected due to the coronavirus disease 2019 (COVID-19) pandemic. The aims of this study were to explore medical students' perception on the school's response and management of clinical rotation during the COVID-19 pandemic and on how it had affected the quality of their education.

Methods: An online questionnaire was distributed to third year medical students at one institution whose clinical rotations re-started during the pandemic. The questions asked about the students' satisfaction with the school's policy and feelings of safety, and the impact of COVID-19 on clinical learning.

Results: The students' perception on the school's response to the pandemic was mixed. Re-commencement of the clinical rotations and procurement of personal protective equipment was positive but a third of students still felt unsafe. The decreased number of hospital patients did not seem to have impacted their overall clinical education with praise on the role of the supervising physicians. Seventy-six-point seven percent of students conferred the positive educational opportunities on medical professionalism presented to them only as the clinical rotation during the ongoing pandemic.

Conclusion: Our observations on the re-commencement of clerkship during this pandemic may help equip medical institutions on future public health crisis.

Key Words: Covid-19, Medical education, Professionalism, Clinical clerkship

\section{Introduction}

Coronavirus disease 2019 (COVID-19) has caused massive disruptions to clinical rotations of medical students across the world. South Korea was one of the earliest countries to experience a mass outbreak of COVID-19 cases. In response, many medical schools suspended their clinical rotations as a precaution, but due to the irreplaceable nature of clinical education, most medical schools in South Korea recommenced clinical rotations within 3 to 4 weeks despite the ongoing pandemic.

At the author's institution, Korea University College of Medicine, which is one of the larger medical schools with three teaching hospitals located within the Seoul
Received: July 8, 2020 • Revised: July 21, 2020 • Accepted: August 4, 2020 Corresponding Author: Young-Mee Lee (https://orcid.org/0000-0002-4685-9465) Department of Medical Education, Korea University College of Medicine, 73 Goryeodae-ro, Seongbuk-gu, Seoul 02841, Korea

Tel: +82.2.2286.1098 email: ymleehj@korea.ac.kr
Korean J Med Educ 2020 Sep; 32(3): 223-229.

https://doi.org/10.3946/kjme.2020.170

eISSN: 2005-7288

(C) The Korean Society of Medical Education. All rights reserved. This is an open-access article distributed under the terms of the Creative Commons Attribution Non-Commercial License (http:// creativecommons.org/licenses/by-nc/3.0/), which permits unrestricted non-commercial use, distribution, and reproduction in any medium, provided the original work is properly cited. 
metropolitan region, clinical rotations were suspended from February 24th 2020, and recommenced 3 weeks later on March 16th for the third-year students. Such a decision required multiple discussions among Korea University Medical College faculty regarding students' and patients' safety, curriculum requirements, and the adequate timing of policy implementation.

The recommencement of clinical rotations was initially met with concern from the third-year student body. But through prompt communication and reassurance on the steps that the faculty and the medical school had undertaken to ensure the safety of the students, the planned schedule for the clinical rotations was able to smoothly re-start.

The impact on clinical education during the pandemic is yet unknown. There could be negative effects from diminished quantity and quality of clinical education or the unknown effects on students' mental health [1,2] but conversely, this situation could present an invaluable opportunity to experience medical professionalism for our future healthcare workforce [3].

This study aims to assess the students' perspective on the impact this disruptive environment has had on their learning by exploring; (1) whether students were satisfied with the medical school's policy for ensuring students' safety, (2) how the COVID-19 situation had influenced educational quality of clinical rotations, and (3) what the students could learn about medical professionalism from real practice.

By early March 2020, around 100 to 250 new COVID-19 cases were being reported daily in South Korea, of which 10 to 20 were in Seoul, the capital. Under such circumstances, our institution recommenced the clinical rotations with the following safeguards against COVID-19 infection: (1) the procurement of five masks per student per week, (2) the establishment of an emergency contact network through which students could report concerns over suspected respiratory symptoms to the vice-deans and the assigned administrative staff of the three teaching hospitals, and (3) the delivery of infection management education by each teaching hospital prior to the recommencement of clinical rotations.

Prior to recommencing clinical rotations, additional precautions were taken to minimize the risk of infection. Using an online questionnaire (Google Forms), students were asked to report any fever or respiratory symptoms, contact history, and travel history. For the small number of students who reported abnormal symptoms, the school followed up their responses via telephone with the findings shared with the corresponding teaching hospitals. During the clinical rotations, students were only assigned to patients who were negative for COVID-19.

\section{Methods}

The aim of the online questionnaire was to explore the medical students' perception on the school's response and management of clinical rotation during the COVID-19 pandemic and on how it had affected the quality of their education. A preliminary pilot study with individual interviews with a selection of third-year clerkship students undertaken by the first author (J.P.) was the base for the development of the contents of the questionnaire, which was later reviewed by the authors Y.M.L. and H.C.L. The finalized version of the survey included satisfaction with the school policy and feeling of safety (seven items), the influence of COVID-19 on clinical learning (seven items), and an open response area to insert suggestions.

A 5-point Likert scale (1: strongly disagree, 2: disagree; 3 neutral, 4: agree, 5: strongly agree) was used for 12 items, and the answers were grouped into three: 
disagree (1+2), neutral (3), and agree (4+5) during the analysis. The remaining two questions offered multiple choice answers, one about situations perceived as dangerous by clerkship students and the second, about lessons only available from clinical rotations during this pandemic. The respondent could choose more than one answer and free space was provided for additional comments.

Invitations to participate in the online survey were sent to 111 third-year medical students undergoing core clinical rotations. The survey was anonymous, and no personal information was gathered. The study received approval from the Institutional Board Review of the Korea University (IRB-2020-0099). Data analysis involved frequency calculations.

\section{Results}

Seventy-three students out of $111(65.8 \%)$ completed

Table 1. Students' Perception on the Medical School's Response to the Clinical Rotation during COVID-19 and Its Influence on Clinical Education $(\mathrm{N}=73)$

\begin{tabular}{|c|c|}
\hline Items & Response $^{\text {al }}$ \\
\hline \multicolumn{2}{|l|}{ Response to school policy and feelings of safety } \\
\hline \multicolumn{2}{|l|}{ Appropriateness of date of recommencing clinical rotations } \\
\hline Satisfied & $45(61.6)$ \\
\hline Neutral & $15(20.5)$ \\
\hline Dissatisfied & $13(17.8)$ \\
\hline \multicolumn{2}{|l|}{ Procurement of face masks by the school } \\
\hline Satisfied & $62(84.9)$ \\
\hline Neutral & $6(8.2)$ \\
\hline Dissatisfied & $5(6.8)$ \\
\hline \multicolumn{2}{|l|}{ Emergency contact network in reducing anxiety } \\
\hline Satisfied & $30(41.1)$ \\
\hline Neutral & $26(35.6)$ \\
\hline Dissatisfied & $17(23.3)$ \\
\hline \multicolumn{2}{|l|}{ Personal infection management education provided by hospitals } \\
\hline Satisfied & $33(45.2)$ \\
\hline Neutral & $23(31.5)$ \\
\hline Dissatisfied & $17(23.3)$ \\
\hline \multicolumn{2}{|l|}{ Supervising physicians' efforts to ensure student safety } \\
\hline Satisfied & $49(67.1)$ \\
\hline Neutral & $19(26.0)$ \\
\hline Dissatisfied & $5(6.8)$ \\
\hline \multicolumn{2}{|l|}{ The perceived feeling of safety against COVID-19 infection } \\
\hline Satisfied & $28(38.4)$ \\
\hline Neutral & $22(30.1)$ \\
\hline Dissatisfied & $23(31.5)$ \\
\hline \multicolumn{2}{|c|}{ Situations during clinical rotations that were perceived as dangerous ${ }^{\text {bl }}$} \\
\hline Interviewing or examining assigned patient & $31(42.5)$ \\
\hline Eating at a hospital cafeteria & $21(28.8)$ \\
\hline Observing at an outpatient clinic & $20(27.4)$ \\
\hline Rounding at wards & $18(24.7)$ \\
\hline Self-studying at student lounges & $12(16.4)$ \\
\hline None & $20(27.4)$ \\
\hline
\end{tabular}




\begin{tabular}{|c|c|}
\hline Items & Response $^{\text {al }}$ \\
\hline \multicolumn{2}{|l|}{ Impact on clinical education } \\
\hline \multicolumn{2}{|l|}{ Reduced number or variety of patients } \\
\hline Agree & $46(63.0)$ \\
\hline Neutral & $9(12.3)$ \\
\hline Disagree & $18(24.7)$ \\
\hline \multicolumn{2}{|l|}{ Reduced opportunities for communicating with patients } \\
\hline Agree & $21(28.8)$ \\
\hline Neutral & $19(26.0)$ \\
\hline Disagree & $33(45.2)$ \\
\hline \multicolumn{2}{|l|}{ Reduced opportunities to perform physical examination on patients } \\
\hline Agree & $24(32.9)$ \\
\hline Neutral & $11(15.1)$ \\
\hline Disagree & $38(52.1)$ \\
\hline \multicolumn{2}{|l|}{ Reduced opportunities to meet supervisors } \\
\hline Agree & $17(23.3)$ \\
\hline Neutral & $13(17.8)$ \\
\hline Disagree & $43(58.9)$ \\
\hline \multicolumn{2}{|l|}{ Reduced time or occasions for feedback from supervisors } \\
\hline Agree & $19(26.0)$ \\
\hline Neutral & $7(9.6)$ \\
\hline Disagree & $47(64.4)$ \\
\hline \multicolumn{2}{|l|}{ Supervising physicians tried their best to ensure the quality of education despite limiting conditions } \\
\hline Agree & $55(75.3)$ \\
\hline Neutral & $14(19.2)$ \\
\hline Disagree & $4(5.5)$ \\
\hline \multicolumn{2}{|l|}{ Exclusive experiences brought upon the pandemic } \\
\hline $\begin{array}{l}\text { Positive aspects of medical professionalism including feeling a sense of duty by observing health professionals } \\
\text { working diligently despite the risk of infection }\end{array}$ & $56(76.7)$ \\
\hline Hospital processes, rules, and infrastructure for controlling COVID-19 & $34(46.6)$ \\
\hline Undesirable professional behaviors or attitudes such as selfishness or no sense of duty & $7(9.6)$ \\
\hline None & $12(16.4)$ \\
\hline
\end{tabular}

Data are presented as number $(\%)$.

COVID-19: Coronavirus disease 2019.

${ }^{a}$ The responses were responded using a 5-level Likert scale (1: strongly disagree, 2: disagree; 3: neutral, 4: agree, 5: strongly agree). To analyze data, those were grouped into three categories $(1+2$ : disagree; 3 : neutral; $4+5$ : agree). b) For these questions, multiple responses were allowed.

the survey. Table 1 shows the students' responses to the survey questions. Positive responses included the appropriateness on the clinical rotation recommencing date $(61.6 \%)$ and the procurement of face masks (84.9\%). However, the students' satisfaction levels were unfavorable on the school's provision of emergency contact networks and the hospital education on personal infection management. In addition, the perceived anxiety by the students was still considerable with only $38.4 \%$ of students reporting that they felt safe from COVID-19 infection. The students responded that they felt unsafe when they were meeting their assigned patients, eating at the hospital cafeteria, and at outpatient clinics. In the open responses section, students exhibited mixed opinions; some displaying satisfaction and gratitude for the school's rapid and effective response whilst several students pointed out the need for better sustainable and transparent communication between the school and the students, such as a more predictable and advanced scheduling notifications. 
Even though there were not many COVID-19 cases in the three teaching hospitals of the authors' medical school, the patient volume actually decreased as patients began to refrain from visiting medical institutions resulting in a reduction on the total number of in- and outpatients which had the potential to impact the educational opportunities for our students during their clinical rotation. Our results showed fewer than $30 \%$ of students reported a reduction in opportunities to communicate with or conduct physical examinations on patients and under a quarter of students found the opportunities for supervisor meetings and feedback time had diminished. On a positive note, $75 \%$ of the thirdyear students were satisfied with the efforts made by their supervisors to ensure the provision of quality education despite the challenging conditions.

COVID-19 presented invaluable opportunities for the rotating clinical students who were able to experience, in close proximity, the health care response provided by health care professionals and medical institutions. Seventy-six-point seven percent of students conferred the positive educational opportunities on medical professionalism presented to them only as the clinical rotation had recommenced even during the ongoing pandemic. Students' free text responses included "clinical rotations should be continued under any circumstances and it was a good opportunity to learn what attitude an aspiring physician should have" and "it was good to learn how hospitals and physicians responded to a pandemic disease and how that response played out." Forty-sixpoint six percent of the students responded that they had learnt about hospital processes and management for the control of infectious diseases such as COVID-19, but a small proportion of students reported the witnessing of undesirable behavior or attitudes by healthcare professionals, such as selfishness or the lack of responsibility during the clinical rotations.

\section{Discussion}

Our results showed that students did not object to recommencing clinical rotations, and their overall responses to the school's policy and procedures for clinical rotations during the COVID-19 pandemic were positive. However, the school's effectiveness in reducing the anxiety felt by the students showed room for improvement. Albeit the school's provision of personal protective equipment (such as high-level face masks) was welcomed, it did not alter the feeling of insecurity felt by the students. We could find that the students demanded a better, more frequent and transparent communication channel between themselves and the school through the open responses. The school administration had met with student representatives who relayed the messages through their online group chat rooms, but a more active and visible efforts of leadership, such as face-to-face interactions, could have improved in conveying how the school was making the students' well-being their highest of priority which in turn could have help reduce student anxiety [4].

An interesting finding in our study was the impact on the quality of education was fortuitously less than initially expected. The inevitable reduction of in- and outpatient numbers during the COVID-19 pandemic did not translate to a proportional decreased opportunity for students to interact with patients. This is because medical students, in consideration of their clinical capacity, are usually assigned to only a limited number of patients [5]. In other aspects, the educational provision by the supervising physicians, rather than patient volume, may be a stronger determinant on the quality of clinical education [5,6]. However, the experiences in our institution might not be a universal one for the rest of the country as curriculums vary 
amongst schools as well as the opportunities for patient contact. Whether such individual efforts can be sustained over the long-term is uncertain; even in hospitals with a low burden of positive COVID-19 patients, supervisors and educators are facing time constraints due to their involvement in various contingency plans against COVID-19. In particular, it is unclear whether the supervising physicians will be able to continue their participation in clinical education at the same level if we suffer a more severe second wave. Preparing for alternatives to the current clinical education method is paramount for the future by identifying activities that can be performed even during lockdowns such as the use of digital media with a selection of virtual patients.

Despite the disruptive situation brought upon COVID19, there were positives identified in our survey. The unusual but invaluable opportunity to learn and cultivate medical professionalism in real-life situations was possible by recommencing clinical rotations in the midst of the pandemic. When severe acute respiratory syndrome struck Hong Kong in 2003, four doctors at the University of Hong Kong paid their ultimate price by succumbing to the virus while caring for patients. Their sacrifice was not in vain as students learnt the true meaning of medical professionalism through their courage [7]. The students can feel an increased sense of duty brought upon by such global health crisis as well as learning to balance duty with acceptable levels of personal risk [3,8]. As shown in our study, the most powerful method of developing medical professionalism is through clinical experiences. Like many selfless medical professionals across the country, our institution's professors who volunteered in Daegu, the epicenter of South Korea's COVID-19 initial epidemic, shared their experiences with medical students after the end of their self-imposed 2-week quarantine period. Hearing vivid first-hand experiences in the heart of the outbreak were priceless educational opportunities for the students, helping them develop a spirit of humanism and altruism, which are key aspects of the hidden or informal curriculum [9]. Education is a constant process; positive learning occurs through displays of excellence, humanism, accountability, and altruism from supervising physicians, but also from the negative incidents that inevitably occur in hospitals, which the students may learn to avoid in the future.

An unavoidable limitation of our study is that the number of respondents was only 73 from a single institution, and their responses may not be representative of the situation faced in other institutions in South Korea. Despite this limitation, our results are significant in that it reveals the point of view of the students on the effects of the COVID-19 pandemic on their clinical learning environment.

In conclusion, through our early experience of recommencing clinical rotations during the COVID-19 pandemic at Korea University Medical College, we were able to observe the changes brought upon clinical medical education, identify several shortcomings we should overcome. COVID-19 may well be one of the biggest challenges that medical professionals of this generation might face, and how we train doctors of the future will be decisive in the success of our efforts in overcoming this challenge. We hope the lessons learnt here could inform hospitals and medical schools to aid them in the response to future public health crisis.

\section{ORCID:}

Jewel Park: https://orcid.org/0000-0003-1375-3565; Hyunmi Park: https://orcid.org/0000-0002-4134-2213; Ji-Eun Lim: https://orcid.org/0000-0003-2633-9347; Hye Chang Rhim: https://orcid.org/0000-0002-7986-6493; Young-Mee Lee: https://orcid.org/0000-0002-4685-9465 
Acknowledgements: The authors wish to thank Hyoung Seok Shin and Eun Jin Lee at Department of Medical Education, Korea University College of Medicine for their technical assistance.

Funding: No financial support was received for this study.

Conflicts of interest: No potential conflict of interest relevant to this article was reported.

Author contributions: JP contributed to the conception and design, acquisition, analysis, and interpretation of data, and drafting of the article. HP contributed to the interpretation of the data, writing and major revision of the article. JEL contributed to the acquisition, analysis, and interpretation of data, and minor revision of the article. HCR contributed to the conception and design, acquisition of data, and minor revision of the article. YML contributed to conception and design, analysis and interpretation of data, and drafting and major revision of the article.

\section{References}

1. Rose S. Medical student education in the time of COVID-19. JAMA. 2020;323(21):2131-2132.

2. Cao W, Fang Z, Hou G, et al. The psychological impact of the COVID-19 epidemic on college students in China.
Psychiatry Res. 2020;287:112934.

3. Shi W, Jiao Y. The COVID-19 pandemic: a live class on medical professionalism. QJM. 2020 May 5 [Epub]. https://doi.org/10.1093/qjmed/hcaal57.

4. Shanafelt T, Ripp J, Trockel M. Understanding and addressing sources of anxiety among health care professionals during the COVID-19 pandemic. JAMA. 2020;323(21):2133-2134.

5. Wimmers PF, Schmidt HG, Splinter TA. Influence of clerkship experiences on clinical competence. Med Educ. 2006; 40(5):450-458.

6. Dolmans DH, Wolfhagen IH, Essed GG, Scherpbier AJ, van der Vleuten CP. The impacts of supervision, patient mix, and numbers of students on the effectiveness of clinical rotations. Acad Med. 2002;77(4):332-335.

7. Patil NG, Chan Y, Yan H. SARS and its effect on medical education in Hong Kong. Med Educ. 2003;37(12): 1127-1128.

8. Khamees D, Brown CA, Arribas M, Murphey AC, Haas MRC, House JB. In crisis: medical students in the COVID-19 pandemic. AEM Educ Train. 2020;4(3): 284-290.

9. Karnieli-Miller O, Vu TR, Holtman MC, Clyman SG, Inui TS. Medical students' professionalism narratives: a window on the informal and hidden curriculum. Acad Med. 2010;85(1):124-133. 